\title{
Simpatia e sociabilidade no pensamento de Hume 1
}

Fernão de Oliveira Salles

fernao.salles@gmail.com

Universidade Federal de São Carlos, São Carlos, São Paulo, Brasil

resumo 0 objetivo deste texto é, primeiramente, expor os contornos gerais as críticas de David Hume ao que o filósofo escocês chamou epicurismo moderno. Trata-se das filosofias de Hobbes e de seus supostos epígonos, que, aos olhos de Hume, elegeram o amor próprio como origem fundamental de nossas ações e juízos. Num segundo momento, trata-se de delinear o lugar central do conceito de simpatia nesta crítica, bem como na constituição da moral humeana.

palavras-chave Hume; Hobbes; Locke; amor-próprio; simpatia; estima

É conhecido o impacto do pensamento hobbesiano sobre a filosofia moral produzida na Grã-Bretanha entre os séculos XVII e XVIII. Tenham sido elas bem ou mal compreendidas, as teses propostas pelo autor do Leviatã acerca da moral, da sociabilidade e da política forneceram um dos principais eixos em torno dos quais se articularam as controvérsias dos filósofos de língua inglesa da época. Não por acaso, tornou-se comum entre os chamados moralistas britânicos - Shaftesbury, Butler, Hutcheson e Smith, entre outros - considerar Hobbes como o primeiro expoente de um "epicurismo moderno2" ou "ceticismo moral", cujo equívoco perigoso estaria em eleger o amor-próprio (self love) como fundamento da distinção entre vício e virtude, e em identificar o auto-interesse como sendo a principal base da aprovação moral e do convívio social. Assim, autores como Francis Hutcheson dirão que Hobbes e os outros 
“epicuristas" ou "céticos morais" preferem "torcer o amor-próprio em mil formatos (shapes) em vez de admitir outro princípio de aprovação [moral] que não o interesse" (HUTCHESON, 2004, p. 93). Ainda seguindo Hutcheson, remetendo todos os sentimentos e juízos ao amorpróprio, tais filosofias ${ }^{3}$ esvaziariam a distinção entre vício e virtude ou, na melhor das hipóteses, a tornariam um tanto quanto artificial e arbitrária.

Não há dúvidas de que Hume integra as fileiras dos críticos dessa concepção egoísta da moral e da natureza humana. Todavia, é de se duvidar que ele responda a esses sistemas da mesma maneira e pelas mesmas razões que um Hutcheson, por exemplo. Com efeito, segundo Hutcheson, para refutar os "céticos morais" é preciso provar que o apreço pela virtude é algo natural, derivado de qualidades próprias das ações e dos agentes morais, as quais seriam percebidas por uma espécie de órgão ou sentido interno do qual os homens são dotados por natureza. Hume, no entanto, em nenhum momento pretende opor a esses sistemas um sentido ou órgão próprio para identificar as qualidades morais dos homens e de suas ações. Mais que isso, ele não parece nem mesmo negar uma certa parcialidade inevitável do indivíduo para consigo próprio, embora procure refutar a tese dos defensores do self-love.

Por isso, para ao menos indicar melhor qual é o teor das críticas de Hume ao egoísmo, tomemos como ponto de partida o texto do $2^{\circ}$ apêndice à Investigação sobre os princípios da moral, onde Hobbes é mencionado, ao lado de Locke, entre os modernos que "sustentaram um sistema egoísta da moral"4 (HUME, 2002, p. 296). Nessas passagens, Hume apresenta uma caracterização geral dessas filosofias e denuncia em sua base a presença de uma certa distorção que cumpre identificar desde o início. A crer em Hume, segundo os moralistas dessa linhagem é um princípio verdadeiro

(...) que seja qual for o afeto (affection) que alguém possa sentir ou imaginar que sente pelos outros, nenhuma paixão é, ou pode ser, desinteressada; que a mais generosa amizade, ainda que seja sincera, é apenas uma modificação do amor-próprio (self-love); e que, ainda que não o saibamos, buscamos apenas nossa própria gratificação, ainda que pareçamos profundamente engajados em projetos (schemes) para a liberdade e a felicidade do gênero humano (HUME, 2002, p. 296). 
Note-se que embora derivem todas as afecções do amor-próprio, tais filósofos não negam a veracidade ou sinceridade de afetos como a amizade ou a humanidade. "Um epicurista ou hobbesiano prontamente admite que existe no mundo algo como a amizade sem hipocrisia ou disfarce (disguise)" (HUME, 2002, pp.296-297). O que eles afirmam é que todas as paixões - incluindo aquelas que aparentemente teriam menos relação com o auto-interesse - são derivadas do egoísmo e podem ser reenviadas ao interesse que tenho por minha própria felicidade ${ }^{5}$. Não por acaso, essas filosofias são descritas por Hume como uma "química filosófica" que busca "reduzir" todos os afetos a uma paixão original. Trata-se, segundo a formulação de Hume na Investigação sobre os princípios da moral, de "explicar toda a afecção/afeto (affection) como se fosse o amor-próprio torcido e moldado numa variedade de aparências por um viés (turn) particular da imaginação" (HUME, 2002, p. 297).

Vê-se que esses sistemas são passíveis de certo refinamento. Como o elemento primordial da "química filosófica", o amor-próprio, é suscetível a diferentes transformações conforme as diferentes inclinações da imaginação, essa paixão poderá dar origem a uma extensa gama de caracteres, distintos uns dos outros. E, é importante notar, essas variações poderão produzir tanto caracteres que estimaremos como sendo virtuosos quanto outros que censuraremos como sendo viciosos. Nos termos do $2^{\circ}$ apêndice:

Estimo o homem cujo amor-próprio está, de algum modo, dirigido no sentido de fazê-lo interessar-se pelos outros e torná-lo proveitoso (serviceable) à sociedade, assim como odeio aquele que não tem consideração por nada além de suas próprias gratificações e deleites (enjoyments) (HUME, 2002, p. 297).

Ora, dizer que louvo o homem útil à sociedade é o mesmo que afirmar que aprovo seu caráter como sendo virtuoso. E o inverso vale para aquele outro sobre o qual recai minha censura. O sistema moral do egoísmo permite que se explique essa variedade de caracteres, bem como a aprovação ou a censura que pesa sobre eles. Todavia, será sempre preciso lembrar que tanto meu juízo quanto a inclinação do homem virtuoso pelo bem dos demais estão, ao fim, fundados no egoísmo e no auto-interesse. A consequiência deste raciocínio é que, ao menos aos olhos de 


\section{4}

Hume, o defensor desse tipo de sistema é levado a considerar que tanto o homem considerado virtuoso quanto o vicioso são, na verdade, movidos pelo mesmo princípio.

Por um viés da imaginação, por um refinamento da reflexão, por um entusiasmo da paixão, parecemos partilhar dos interesses dos demais e nos imaginamos despojados de toda consideração egoísta; mas, no fundo, o patriota mais generoso e o sovina mais mesquinho, o mais bravo herói e o mais abjeto covarde têm, em todas as suas ações, igual consideração por sua própria felicidade e bem-estar (HUME, 2002, p. 296).

Passagens como essa indicam em que medida a moral do egoísmo é criticável para Hume. Aos olhos do filósofo escocês, quando situam a origem de nossas motivações no amor-próprio, autores como Hobbes e Locke nivelam e até mesmo igualam o caráter do homem corajoso, do covarde, do patriota e do sovina. Pior que isso, ao fazerem do auto-interesse a medida de nossos juízos e de nossa estima esses filósofos os reduzem a um cálculo que parte sempre da restrita perspectiva do egoísmo, que sempre toma por padrão a minha felicidade, a minha satisfação, o meu bem etc.

Hume não nega o fato de que grande parte de nossas ações seja moldada por motivos egoístas e pelo auto-interesse. Em vez disso, ele reconhece que o "amor-próprio" é um princípio poderoso da natureza humana e que o interesse do indivíduo está constantemente mesclado aos da sociedade. Desse modo, se o filósofo escocês se distancia de um autor como Hobbes, não é porque este último levou em conta o amor-próprio e o egoísmo na construção de seu sistema. O problema dos sistemas do egoísmo, ao que tudo indica, está no fato de que eles consideram a natureza humana de forma extremamente parcial e limitada. Em outras palavras, há uma grande parcialidade na promoção do egoísmo ao posto de princípio único das ações e juízos dos homens.

Estou consciente de que, falando de modo geral, as representações desta qualidade têm sido levadas longe demais; e as descrições desse aspecto particular do gênero humano, que certos filósofos tanto se deleitam em compor (form), são tão afastadas da natureza quanto quaisquer relatos sobre monstros, com os quais nos deparamos nas fábulas e romances. Longe de pensar que os homens não possuem afeição por nada a não ser eles mesmos, sou da opinião de que, 
embora seja raro encontrar algum que ame uma pessoa sequer mais que a si mesmo, é igualmente raro encontrar alguém em quem todos os afetos gentis (kind affections), considerados em conjunto, não sobrepujem os egoístas (HUME, 1978, p. 487).

A julgar por passagens como essa, os sistemas morais fundados no egoísmo falham justamente porque são parciais quando pretendem derivar todas as ações e juízos dos homens desta paixão que é o amor-próprio. E, embora seja verdade que essas teorias não causam danos à prática ou à conduta $^{6}$, elas resultam em prejuízos para a "ciência especulativa da natureza humana". Com efeito, elas descrevem tal natureza de maneira distorcida e, se levarmos a sério a comparação supracitada com as fábulas e romances, fantasiosa. A ênfase excessiva no egoísmo faz com que se perca de vista a questão que realmente deveria interessar a uma ciência especulativa do homem. Pois, muito mais do que compreender supostas modificações do amor-próprio, trata-se de entender como, apesar da tensão entre uma tendência à sociabilidade e o amor-próprio, ambos presentes em nosso temperamento natural (natural temper), a união dos homens em sociedade termina por se estabelecer.

Pois, deve-se admitir que, embora circunstâncias (circumstances) da natureza humana possam tornar necessária uma união, e embora essas paixões da lascívia (lust) e da afeição natural (natural affection) pareçam torná-la inevitável, há outras particularidades de nosso temperamento natural e das circunstâncias externas que são muito inconvenientes e até mesmo contrárias à requerida conjunção. Entre as primeiras podemos estimar com justeza nosso egoísmo como sendo a mais considerável (HUME, 1978, p. 486).

Por isso, contra essa concepção da natureza humana é preciso apresentar uma outra que nos permita ultrapassar o ponto de vista do auto-interesse, ainda que sem excluí-lo ou eliminá-lo. Pois, se insistirmos na perspectiva estreita dos sistemas do egoísmo seremos incapazes de compreender verdadeiramente as questões da moral e da política. Com efeito, neste caso tomaremos como ponto de partida uma concepção de natureza humana desfigurada devido à consideração excessiva do amor-próprio e do auto-interesse. 
Esta má compreensão da natureza do homem deve ser combatida, em primeiro lugar, através da simples exibição de exemplos que parecem ser evidentemente contrários ao egoísmo. É preciso lembrar, antes de tudo, que os homens possuem sentimentos, paixões e emoções que não podem ser reduzidas ao simples amor-próprio. Para isso, Hume vai invocar o testemunho da experiência comum e dos usos da linguagem, no sentido de tornar sensível a distinção que fazemos entre paixões ou afecções sociáveis e egoístas.

Mesmo para o observador mais descuidado parece haver disposições como a benevolência e a generosidade, afecções como o amor, a compaixão e a gratidão. Esses sentimentos têm suas causas, efeitos, objetos e modos de operação marcados pela linguagem comum e pela observação e claramente distinguidos daqueles das paixões egoístas (HUME, 2002, p. 298).

Numa primeira etapa da argumentação Hume vai, então, empregar diversos exemplos para esvaziar a premissa do egoísmo, segundo a qual toda afecção passional e todo motivo devem ser reduzidos ao amor-próprio. É com esse objetivo que o texto irá começar por lembrar ao leitor de que diversos animais dão mostras de "amabilidade" tanto para com indivíduos de sua espécie, quanto para com os homens, sem que tenhamos nenhum indício que nos permita derivar suas ações de algum interesse próprio secretamente dissimulado. Trata-se de uma tópica antiga, segundo a qual, mesmo entre as feras haveria algum interesse que escapa ao mero auto-interesse. Entre os homens, os exemplos parecem ser ainda mais fortes. $\mathrm{O}$ amor entre os sexos, a ternura pela prole e a gratidão fornecem amostras eloqüentes de afecções que, aparentemente, nos levam a nos interessarmos pelo bem do outro, sem que levemos em conta se este nos seria de algum modo vantajoso. Em vez disso, sugere Hume, em alguns casos temos exemplos inequívocos de ações que são praticadas tendo em vista o bem de outrem, em vez da vantagem do agente.

Que interesse pode ter em vista uma mãe afetuosa que perde sua saúde devido à assídua assistência que dispensa a seu filho doente; e que, quando libertada da escravidão daquela assistência, devido à morte deste, definha e morre de pesar? (HUME, 2002, p. 300). 
Uma coisa, porém, é exibir exemplos que aparentemente contradizem a tese hobbesiana e outra é mostrar porque essa tese não poderia estar correta. Hume, aliás, reconhece que sentimentos como a gratidão e o amor pela prole poderiam ser reduzidos ao amor-próprio - ainda que às custas de muito engenho e de algum artificio. Essa, é preciso lembrar, era a operação desempenhada por aquela "química" filosófica que caracterizava os sistemas do egoísmo. Contudo, ocorre que, embora essa redução seja factível pelo raciocínio, ela não é necessária e nem mesmo tem a seu favor a vantagem de ser a hipótese mais econômica e mais provável para explicar essas afecções. Nas palavras do autor

Ademais, se considerarmos corretamente essa matéria, veremos que a

hipótese que admite uma benevolência desinteressada, distinta do amor-próprio, tem realmente mais simplicidade e é mais conforme à analogia da natureza do que a hipótese que pretende reduzir toda amizade e humanidade (humanity) a esse último princípio (HUME, 2002, p. 301).

No entanto, para refutar os sistemas do egoísmo e afirmar a possibilidade de um interesse puro dos homens por seus semelhantes não basta mostrar que há outras filosofias mais simples e elegantes que aqueles. Assim, se queremos argumentar que as paixões sociáveis não são modificações do egoísmo natural dos homens, temos que apontar quais princípios tornariam possível que eu me interessasse por meus semelhantes, sem ter em vista meu próprio benefício. Dado que Hume não nega integralmente o egoísmo, cabe procurar o que faz o indivíduo deixar de lado essa perspectiva, sempre parcial para consigo mesmo, para adotar uma outra que o faz considerar em pé de igualdade os outros homens e, no limite, o bem público?

A resposta de Hume passa, até certo ponto, pelo princípio da utilidade. Boa parte da Investigação sobre os princípios da moral insiste neste aspecto e mostra que o apreço que temos pelas virtudes sociais (benevolência, humanidade etc...) deriva, em grande medida, das conseqüências benéficas que tiramos dessas qualidades de caráter. Estimamos e aprovamos o homem dotado de caráter benevolente e humanitário porque sabemos da "felicidade e satisfação que a sociedade obtém de sua convivência e de seus bons oficios". O mérito associado à benevolência e outras qualidades ou virtudes a ela semelhantes advém de sua "tendência 


\section{8}

a promover os interesses de nossa espécie." Essa utilidade esclarece porque estimamos e louvamos o caráter dotado de virtudes benéficas para a sociedade e para a espécie humana.

A noção de utilidade é fundamental para explicar a estima que temos por certos caracteres e para entendermos, em parte pelo menos, a distinção entre a virtude e o vício. Todavia, aparentemente, ela não basta. Como afirma Hume: "A virtude é considerada um meio para um fim. Um meio só tem valor se o fim tem valor” (HUME, 2002, p. 619). É necessário explicar porque tomamos interesse por esse fim que a virtude é capaz de promover. Noutras palavras, temos que explicar porque nos interessamos por algo tão geral e distante de nossa experiência comum quanto o bem público ou a utilidade pública.

O próprio Hume não se cansa de mostrar que somos mais fortemente afetados por aquilo que nos é mais próximo ou que está mais diretamente ligado a nós. "É certo", podemos ler no Tratado da natureza humana, "que a imaginação é mais afetada pelo particular que pelo geral, e que os sentimentos sempre são movidos com mais dificuldade quando seus objetos são, em qualquer grau, vagos e indeterminados" (HUME, 1978, p. 580). Que eu valorize e louve as qualidades que dizem respeito a meu próprio bem estar é perfeitamente compreensível. É daí, diga-se de passagem, que decorre o poder de persuasão dos sistemas baseados no egoísmo. Mas a idéia de bem público é demasiadamente geral e, por isso mesmo, em alguma medida, vaga e indeterminada. Cabe, portanto, ao menos mostrar por que as qualidades ou ações que contribuem para este bem nos são agradáveis e se tornam objeto do louvor e do interesse dos homens. É necessário mostrar o que torna possível que um indivíduo seja capaz de realizar duas operações distintas, embora eminentemente ligadas entre si: 1) ser realmente afetado pela consideração do outro e, no limite, pelo bem público; 2) ampliar sua perspectiva naturalmente singular e tornarse capaz de levar em conta o interesse público.

É a noção de simpatia ${ }^{7}$ que fornece a Hume as condições para encaminhar uma solução para essas dificuldades. A simpatia, esse "princípio muito poderoso da natureza humana", permite ao filósofo escocês explicar como se dá a comunicação entre indivíduos cujo temperamento natural, como vimos, comporta algum grau de egoísmo, e cujas ações são suscitadas por diversas inclinações e paixões. Essa operação pode ser 
flagrada em ação em diversas circunstâncias e, na Investigação sobre os princípios da moral, é uma paráfrase de Horácio que dá a deixa para Hume explicar o papel por ela desempenhado na constituição das condições para a sociabilidade:

O semblante humano, diz Horácio, toma emprestados os sorrisos e lágrimas do semblante humano. Reduza uma pessoa à solidão e ela perderá todo o deleite, exceto talvez o deleite de tipo sensual e o de tipo especulativo, pois, os movimentos de seu coração não serão estimulados (forwarded) por movimentos correspondentes em seus companheiros (fellow-creatures). Os sinais de pesar (sorrow) e lamentação, embora arbitrários, nos afetam com melancolia; mas seus sintomas naturais, como lágrimas, gritos e gemidos, nunca falham em produzir compaixão e desconforto (uneasiness) (HUME, 2002, p. 220).

A paráfrase de Horácio chama a atenção para a nossa capacidade de sermos tocados pelos sinais externos de sofrimento e de alegria, visíveis nas feições de nossos semelhantes. "Assim como as faces humanas riem com as que riem também choram com as que choram" (Horácio, Ars poetica $)^{8}$. A visão do sofrimento faz com que nos coloquemos no lugar daquele que sofre. A simpatia é justamente o mecanismo que torna possível esse transporte da imaginação. É ela que confere densidade à idéia que faço do sofrimento ou do prazer dos outros homens, pois, é por ela que essa idéia adquire a força de uma impressão ou paixão9 ${ }^{\text {. É através }}$ desse mecanismo que a idéia que tenho de uma paixão aparentemente presente no outro se torna presente em mim, adquire força e vivacidade e, numa palavra, torna-se propriamente uma paixão. Isso explica, por exemplo, desde a aflição e compaixão que sentimos quando assistimos ao sofrimento alheio ou mesmo um fato corriqueiro como o interesse despertado pelas apostas numa mesa de jogo:

Podes observar que, onde há muitas mesas de jogo, todos se dirigem àquelas em que estão acontecendo as maiores apostas, mesmo que ali não encontrem os melhores jogadores. Ter a visão ou, ao menos, a imaginação de fortes paixões surgindo de uma grande perda ou de um grande ganho afeta por simpatia o espectador, dá a ele alguns toques da mesma paixão e lhe serve de entretenimento momentâneo" (HUME, 1985, p. 217). ${ }^{10}$ 
A "simpatia ou comunicação", diz-nos Hume no Tratado da natureza humana, "nada mais é que a conversão de uma idéia em uma impressão pela força da imaginação" (HUME, 1978, p. 427). Este processo, convém notar, é descrito em termos muito semelhantes àqueles que Hume emprega ao mostrar como se dá a gênese de nossas crenças derivadas da relação de causa e efeito ${ }^{11}$. No último caso, pela influência do hábito a imaginação era levada a conceber, com a força e a vivacidade de uma impressão dos sentidos, a idéia de um objeto ainda ausente. Isto é, essa idéia tornava-se uma crença na medida em que adquiria maior grau de força e vivacidade e se aproximava, no que concerne a essas duas qualidades, de uma impressão.

No caso da simpatia algo análogo ocorre no que diz respeito às paixões de outrem. A idéia que delas faço torna-se viva o suficiente para que ela se converta nessas mesmas paixões. Assim, torna-se possível que eu desloque minha perspectiva e me coloque no lugar deste outro. Esse deslocamento vem, no entanto, acompanhado do fato de que me torno também sensível a essas paixões. De um só golpe, passo, em algum grau, a padecer dessas afecções e amplio meu ponto de vista, agregando o ponto de vista que antes era de um outro indivíduo. Conforme o Tratado:

Uma vez que a simpatia nada mais é que uma idéia vívida convertida numa impressão, é evidente que, considerando a condição futura possível ou provável de qualquer pessoa, nós podemos entrar nela com uma concepção tão vívida, que é como se ela nos dissesse respeito; e por tais meios podemos ser sensíveis a sofrimentos e prazeres que nem se referem a nós nem têm existência real alguma no presente instante (HUME, 1978, pp. 385-386).

Ou ainda:

Como em cordas igualmente afinadas, nas quais o movimento de uma se comunica para as restantes, todas as afecções (affections) passam prontamente de uma pessoa à outra e produzem movimentos correspondentes em todas as criaturas humanas (HUME, 1978, p. 576).

Assim, pela simpatia as paixões e sentimentos são comunicados a diferentes sujeitos. Esse princípio vivifica as idéias e anima algumas paixões. Isso explica não só porque nos compadecemos ou nos alegramos com 
nossos semelhantes, mas fornece algumas das razões pelas quais somos tocados ao contemplarmos a representação de diversas paixões, sentimentos e caracteres quando estamos diante de um quadro, quando lemos uma obra literária ou quando assistimos uma peça de teatro. Nessas situações, simpatizamos com as personagens e somos levados a trocar nosso ponto de vista particular assumindo um outro muitas vezes mais geral. De fato, há uma forte analogia entre a situação do público de uma peça de teatro, por exemplo, e o simples convívio dos homens nas circunstâncias mais corriqueiras da vida em sociedade. Em ambos os casos, somos espectadores afetados por circunstâncias particulares e por aqueles sinais externos das paixões aos quais se referia Horácio, na passagem supracitada.

(...) as mentes dos homens são como espelhos umas para as outras, não só porque refletem as emoções das demais, mas porque esses raios de paixões, sentimentos e opiniões podem reverberar diversas vezes, decaindo gradual e insensivelmente. Assim, o prazer que um homem rico obtém com seus bens, projetado sobre o observador, causa, neste, prazer e estima (steem); esses sentimentos, por sua vez, sendo objetos de percepção e simpatia, aumentam o prazer do proprietário; e, sendo mais uma vez refletidos, tornam-se um novo fundamento de prazer e estima (steem) no observador (HUME, 1978, p. 365). ${ }^{12}$

Todavia, Hume é o primeiro a notar que a eficácia desse mecanismo de espelhamento e comunicação das paixões depende de uma série de circunstâncias nem sempre presentes e se encontra encerrado em limites um tanto quanto estreitos. No que concerne a essas limitações, em primeiro lugar, é preciso reconhecer que nossa simpatia é originalmente restrita àqueles que nos são queridos ou próximos. Na fórmula sucinta de Deleuze: “A verdade é que o homem é sempre o homem de um clã, de uma comunidade" (DELEUZE, 2001, p. 31). Como diz o próprio Hume no Tratado: "cada homem particular ocupa uma posição particular em relação aos outros" e a dificuldade da sociabilidade está justamente em ampliar nosso interesse e nosso juízo até que se consiga estabelecer um "ponto de vista firme e geral", que permita a superação dessas particularidades.

Em suma, ao estabelecer uma comunicação com as paixões dos outros homens, a simpatia é capaz de ampliar meu interesse e minha perspecti- 
va. Mas, sua esfera de ação está, ao menos inicialmente, limitada àqueles que se conectam a mim por alguma relação. Por si sós a simpatia e as virtudes a ela relacionadas, como a benevolência e a humanidade, não dão conta do interesse público, nem da sociabilidade. Nossa generosidade natural, como dirá Hume, é limitada e insuficiente para fazer contrabalançar nosso egoísmo. Daí, a necessidade da instituição das regras da Justiça e do refinamento e ampliação daquela simpatia natural.

Pode-se, portanto, perguntar como a simpatia forneceria uma resposta aos sistemas do egoísmo. Afinal, Hume parece admitir que deixados unicamente sob a influência deste princípio provavelmente os homens nunca chegariam a ultrapassar os vínculos familiares e laços de amizade para estabelecer formas de sociabilidade mais abrangentes e complexas. É verdade, ainda, que é necessário estabelecer as regras da Justiça para assegurar o bem-público, e evitar que a parcialidade e o auto-interesse tragam "desordem para o mundo". Mas, como enfatiza a conclusão do Livro III do Tratado da natureza humana, o "bem-público nos é indiferente, a não ser na medida em que a simpatia nos faz tomar interesse por ele" (HUME, 1978, p. 618). Assim, embora não seja condição suficiente para a sociabilidade, ela é sem dúvida necessária.

Foi isso que autores como Hobbes e Locke parecem ter deixado passar, ao menos aos olhos de Hume. Com efeito, priorizando o amor-próprio em sua concepção do homem e da vida em sociedade, os partidários dos "sistemas do egoísmo" consideraram que a realização da vida em sociedade depende, sobretudo, da instituição de uma medida comum que imponha limites ao auto-interesse e aos apetites dos homens.

Não estranha que, para o filósofo escocês, o problema da moral e da política seja de outra ordem. Não surpreende que a questão consista, em grande medida, em descobrir meios de ampliar tanto nosso juízo quanto nosso interesse. Numa palavra: meios para alargar e refinar nossa simpatia natural. Daí, diga-se de passagem, a importância do tema do cultivo das artes, das ciências, das maneiras e da educação na obra de Hume. Talvez possamos dizer que, de um ponto de vista humeano, foi isso que escapou aos "epicuristas modernos". 
${ }^{1}$ Uma primeira versão deste texto foi apresentada no $2^{\circ}$ Colóquio Justiça,Virtude e Democracia, promovido pelo Programa de Pós-Graduação do Departamento de Filosofia e Metodologia das Ciências da UFSCar. Agradeço a todos os colegas que tiveram a gentileza de discuti-lo na ocasião.

2 Sobre o sentido desta comparação um tanto pejorativa entre Hobbes e o epicurismo cf. JAFFRO, 2000, p. 14: "Essa etiqueta designa muitas teses. Aquela que nega a naturalidade da virtude porque ela não pode advir senão da obediência a uma lei divina ou da obrigação que acompanha uma lei humana; aquela que nega a naturalidade da virtude porque ela é uma convenção social; aquela que nega a naturalidade da virtude porque ela não é senão uma paixão ou interesse egoísta disfarçado." Cf. ainda o próprio Hutcheson: "Há duas opiniões inteiramente opostas sobre este assunto; a dos antigos epicuristas, belamente explicada no livro I do De finibus, de Cícero, a qual foi ressuscitada (revived) pelo senhor Hobbes: 'Que todos os desejos da mente humana, ou de todas as naturezas pensantes, são redutíveis ao amor-próprio, ou desejo de felicidade privada; e que é deste desejo que brotam (flow) todas as ações de qualquer agente"” (HUTCHESON, 2002, p. 134).

3 Vale lembrar que em se tratando de Hutcheson e, posteriormente, de Hume o rol dos "epicuristas" deve incluir ainda John Locke e Bernard Mandeville.

4 Os trechos da Investigação sobre os princípios da moral aqui reproduzidas foram extraídos da clássica edição de Selby-Bigge e são citadas aqui conforme sua paginação. As traduções foram feitas por nós a partir do cotejo do original com a edição brasileira da mesma obra, publicada pela Fundação Editora da Unesp em 2003, com tradução da lavra de José Oscar de Almeida Marques. O mesmo se aplica às passagens do Tratado da natureza humana citadas neste artigo. Também elas foram todas extraídas da edição de Selby-Bigge e são citadas aqui conforme a paginação da mesma edição. Novamente, é preciso ressaltar que as traduções aqui utilizadas foram feitas a partir do cotejo do texto original com a edição brasileira da mesma obra, publicada conjuntamente pela Imprensa Oficial SP e a Fundação Editora da Unesp em 2000, com tradução de Débora Danowski.

5 Noutras palavras, não se trata de acusar esses filósofos de desconsiderarem sentimentos ditos altruístas ou sociáveis, como a amizade etc. Mas de apontar que eles tudo reduzem ao egoísmo.

${ }^{6}$ A crer em Hume o exemplo maior do caráter inócuo dessas teorias para a prática estaria na própria conduta de seus maiores defensores: "Probidade e honra não eram estranhas a Epicuro e sua seita. (...) E entre os modernos, Hobbes e Locke, que sustentaram o sistema egoísta da moral, viveram vidas irreprocháveis (...)" (HUME, 2002, p. 296).

7 É importante assinalar que a simpatia desempenha diversas funções no pensamento de Hume. Ela é fundamental para explicar o juízo estético, as paixões indiretas, para assegurar a possibilidade de uma ciência da natureza humana e para fornecer uma explicação para a questão da sociabilidade. Embora, a rigor essas muitas facetas da simpatia estejam imbricadas, umas nas outras, vamos nos restringir aqui apenas à última delas. Quanto a esse vários níveis cf., por exemplo: MERCER, 1995; SUZUKI, 1999; TWEYMAN, 1995.

${ }^{8}$ A tradução deste trecho de Horácio foi extraída da edição brasileira da Investigação sobre os princípios da moral. Cf. HUME. 2003, p. 286, nota 4.

doispontos, Curitiba, São Carlos, vol. 7, n. 2, p.91-105, outubro, 2010 
9 É por isso que a simpatia é fundamental para que compreendamos as chamadas paixões indiretas. Sobre este ponto cf., SUZUKI, 1999, p. 34: "Todas as paixões mais importantes aquelas que Hume chama de 'paixões indiretas', pois dependem de uma 'dupla relação de impressões e idéias' - são condicionadas pela simpatia. Amor, ódio, ambição, avareza, curiosidade, vingança ou lascívia - como quer que sejam avaliadas, positiva ou negativamente, o fato é que tais paixões não existem sem a participação do outro. Elas seriam paixões apáticas, não teriam "força alguma, se tivéssemos que abstrair inteiramente dos pensamentos e sentimentos dos outros (HUME, 2002, 363).”

10 A tradução deste trecho do ensaio Da tragédia foi-nos gentilmente cedida por Márcio Suzuki e Pedro Paulo Pimenta.

11 Sobre essa semelhança entre a crença e a simpatia cf.o ensaio de TWEYMAN, 1995, pp. 430-432.

12 É importante notar que ao vertermos esse trecho para a língua portuguesa adotamos quase que integralmente a solução de tradução da edição brasileira do Tratado, citada em nossa bibliografia.

\section{Referências bibliográficas}

DELEUZE, G. 2001. Empirismo e subjetividade: ensaio sobre a natureza

humana segundo Hume. Trad. L. B. Orlandi. São Paulo: Editora 34.

HUME, D. 1985. Essays moral, political and literary. Indianapolis: Liberty Fund.

HUME, D. 1978. A Treatise of Human Nature. Ed. Selby-Bigge. Oxford: Clarendon Press.

HUME, D. 2000. Tratado da Natureza Humana. Trad. D. Danowski. São Paulo: Editora Unesp / Imprensa Oficial.

HUME, D. 2002. An Inquiry concerning the Principles of Morals. In Hume Inquiries. Ed. Selby-Bigge. Oxford: Clarendon Press.

HUME, D. 2003. Investigação sobre os princípios da moral. In: Investigações sobre o entendimento humano e sobre os princípios da moral. Trad. J. O. A. Marques. São Paulo: Ed. Unesp.

HUTCHESON, F. 2002. An essay on the nature and conduct of the passions and affections, with illustrations on the moral sense. Indianapolis: Liberty Fund. 
JAFFRO, L. 2000. "La formation de la doctrine du sens moral: Burnet, Shaftesbury, Hutcheson". In JAFFRO, L. éd., Le sens moral: une histoire de la philosophie morale de Locke à Kant. Paris: PUF.

MERCER, P. 1995. "Hume's concept of sympathy". In TWEYMAN, S. ed., David Hume: critical assesments. London: Routledge.

SUZUKI, M. 1999. "O homem do homem e o eu de si-mesmo", Discurso, São Paulo, no 30, pp. 25-61.

TWEYMAN, S. 1995. "Sympathy, belief, and the indirect passions". In TWEYMAN, S. ed., David Hume: critical assesments. London:

Routledge. 